\title{
The Persistence of Inter-Regional Hierarchy in Technology Transfer Networks: An Analysis of Chinese Patent Licensing Data
}

\author{
Ilwon Seo*, Jung Won Sonn*^ \\ * Bartlett School of Planning, University College London \\ $\wedge^{\wedge}$ Corresponding author
}

\begin{abstract}
This paper asks whether the technological development of a nation reduces inter-regional hierarchy in knowledge flow. We examine two scenarios that are the alternative to each other. The first is what we call, the globalization of regional innovation system/ weakening of inter-regional hierarchy scenario: As many regions develop their niches in the global economy, the national "anchor" regions loses its relative importance as the importer and distributor of new knowledge, rendering the domestic inter-regional hierarchy less significant as a result. The second scenario is the globalization of national innovation system/ persistence of inter-regional hierarchy. The nation's traditional anchor region becomes even more active in importing technology and distributing it to other regions of the country. To test which scenario is closer to reality, we employ social network metrics to analyse inter-regional technology diffusion networks using Chinese patent licensing data for the 19982013 period. Our findings support the second scenario, showing that the influence of the traditional anchor region persists in the hierarchical network structure as new cities enter the network. We found five anchor regions: the three usual suspects-Beijing, Shanghai, and Shenzhen—plus two that were slightly unexpected—Dongguan and Suzhou.
\end{abstract}

Keywords: Anchor region, inter-regional knowledge flow, technology transfer networks, national system of innovation, Chinese patent licensing 


\section{Introduction}

How a region acquires exogenous knowledge, and utilizes it to re-create new knowledge is critical in regional economic growth (Audretsch and Keilbach 2008, Capello, Caragliu, and Nijkamp 2010, Choi and Cho 2015, Choi and Choi 2017, Cooke 2004, Coe and Helpman 1995, Park 2016, Sonn and Park 2011). In a fast-growing economy, in particular, such knowledge acquisition process is even more important as means of extending the knowledge base (Chatterji 1996, Jonash 1996, Kim 1997), and acquiring informal channels of tacit knowledge (Cohen and Levinthal 1989, Huber 1991). The utilization of exogenous knowledge as opposed to domestic $R \& D$ is advantageous because it can reduce the uncertainty of the latter and facilitates connections with the creators of advanced knowledge across national borders (Capon and Glazer 1987, Granstrand et al. 1992, Chatterji and Manuel 1993, Bathelt and Henn 2014).

Although previous studies have revealed the importance of externally acquired knowledge to a region's innovative capacity, few have explored the characteristics of inter-regional interactions in the diffusion of imported knowledge within the nation. Externally acquired knowledge is an important part of the catching-up process because one of the most effective ways to enhance a region's technological capabilities is by importing, assimilating, and improving exogenous technologies across regions (Kim 1998, Liu and White 2001). One critical facture in stimulating technology flows over geographical distance is regional hierarchy (Verspagen 2010, Storper and Walker 1989). The basic idea here is that traditional core regions, or what we will call "anchor regions," owing to the variety and convergence of their economic activities, generate a wider range of innovative outputs than peripheral regions (Verspagen 2010). Given such a hierarchy in the national system of innovation (NSI), some regions specialize in providing technologies to other regions. Some relational approaches to urban and regional economic development tend to emphasize the direct connection between global flow and local processes of technology production. For example, authors from the global production network (GPN) claim that a regional economy is usually "coupled" with a multi-national company (MNC) (Ernst and Kim 2002, Yeung 2016). Compared to earlier approaches that focus on the external dependency of regions, their contribution lies in revealing the relationship between external inputs and the region's development lies in the non-passivity of local actors (Liu and Yeung 2008, Yeung 2009). It is, however, not clear whether the domestic core-periphery relations in technology production persist; this paper attempts to tackle this lack of clarity. 
One approach to the linkages between regional roles and structures is to track the flow (source and destination) of the technologies underpinning the economic activities. But it is not easy to trace those invisible pathways, mainly due to their tacit and intangible nature (Asheim and Gertler 2005). Patent licensing records provide reliable evidence that enables us to track codified technology flows between regions; this is because the records clearly reveal both the origin and the destination of the technology flow.

In recent years, many researchers have applied social network analysis techniques to technology diffusion across space (Ter Wal and Boschma 2009, Cantner and Graf 2006, Boschma, Balland, and Kogler 2014). Social network analysis allows us to understand not only the structural characteristics of all the nodes at a macro level, but also the individual roles of these nodes. This approach has been used to examine regions' functional classifications when transmitting technology within domestic technology transfer networks (Hong 2008, Wang et al. 2015). This study tackles a further, and as yet unanswered, question: what are the anchor regions' internal processes and their roles in the technology flow at the national level? We look at China to answer this question. China offers a perfect ground because: 1) its territory is vast, which makes regional dynamics of innovation easily observable (Jiang and Kim 2016), and 2) its technological capacity has grown quickly over the last few decades, after the global flow of information became a natural part of technology development.

The remainder of the paper is organized as follows. Section 2 reviews the literature on technology flows in a network and the roles of leading actors in innovation systems. Section 3 describes the data and metrics. Section 4 analyzes the structural properties of technology licensing networks. Section 5 explores anchor regions by investigating knowledge exchange patterns and examining whether the hierarchy in technology persists. Section 6 sums up the major findings and offers implications.

\section{The role of the anchor region in the hierarchy of the innovation system}

The literature on the NSI focuses on networks that link institutions. The building blocks of the system are institutions such as firms, universities, and governments, among others. From a regional development point of view, such an approach is characterized by what geographers call "methodological statism", in which the national boundary is treated as the single divider of societies and economies (Dalby and Tuathail 1998). In this approach, little consideration is paid to spatial differences within the national boundary. On the other 
hand, geographical approaches to innovation tend to focus on the region as spatial unit of analysis and downplay the importance of a NSI. This paper attempts to reconcile these two approaches by locating the region and its innovation system as the spatial building blocks of a national innovation system.

To better explain this idea, we need to elaborate the definition of the anchor region that we mentioned earlier in this paper. An anchor region is a region that imports advanced technology from overseas, assimilates and improves that technology, and produces its own technology for other regions within the country. As such, the anchor region is the leading actor within NSI. This idea was inspired by the "anchor firm" concept employed by Feldman (2003) and others. Within an industrial cluster, the "anchor firm" might increase the innovative activities of other firms through externalities (Feldman 2003, Von Hippel 1994). The critical roles of anchor firms in a cluster or industry include assimilating external technologies, reproducing them within a region, and facilitating the growth of innovative activities among neighbors (Peri 2005).

If the anchor firm plays such important role in a regional economy, can a region play a similar role in a national economy? Powell (2003) argues that a firm is not a hierarchy in the sense of a Weberian ideal bureaucracy, within which decisions are made at the top, relayed to the bottom without any loss of information, and always obeyed without resistance or modification. In fact, a firm is a collection of relatively strong, dense networks between divisions and employees, layered on top of each other. If this description is accurate, dense, geographically proximate networks within a region will allow us to treat a regional economy like a structure in a firm, to a certain degree. In fact, researchers have accumulated ample evidence to suggest this, drawn from their approaches to topics ranging from 1980s' industrial districts to today's evolutionary economic geography (Capello and Varga 2013, Pyke and Sengenberger 1992, Russo 1985, Boschma and Ter Wal 2007). It therefore seems plausible that a region might play a critical role in assimilating and diffusing exogenous knowledge, within a NSI. We will call such a region an "anchor region".

Firms and other organizations in an anchor region import, assimilate, and improve upon the foreign technology. The various local channels of knowledge spillovers, such as informal industry talks, formal partnerships between organizations, and shared labour markets, help other organizations in the same region take advantage of important technology. An anchor firm's assimilation of foreign technology can, therefore, trigger assimilation by an entire region. The anchor region will then pass on its technology - a combination of imported 
and homegrown technology developed in-house - to other regions with lower rankings in the nation's technological hierarchy.

This mechanism of technology diffusion/learning within a national system of innovation may be because the spatial distribution of absorptive capacity is uneven. Different regions have different regional environments, with different levels of absorptive capacity, leading to overall disparities in absorptive capacity (Verspagen 2010). An organization with limited absorptive capacity is likely to source technology from within its immediate cultural and geographical environs (Caniëls and Verspagen 2001). This implies that a region which is ranked lower in a nation's technological hierarchy is more likely to learn from the nation's anchor region than from elsewhere. This process is self-reinforcing. Once a link has been established, it can be exploited repeatedly, owing to the path dependency derived from the potential risks of sunk costs and uncertainty (Hong 2008, Sun and Liu 2016).

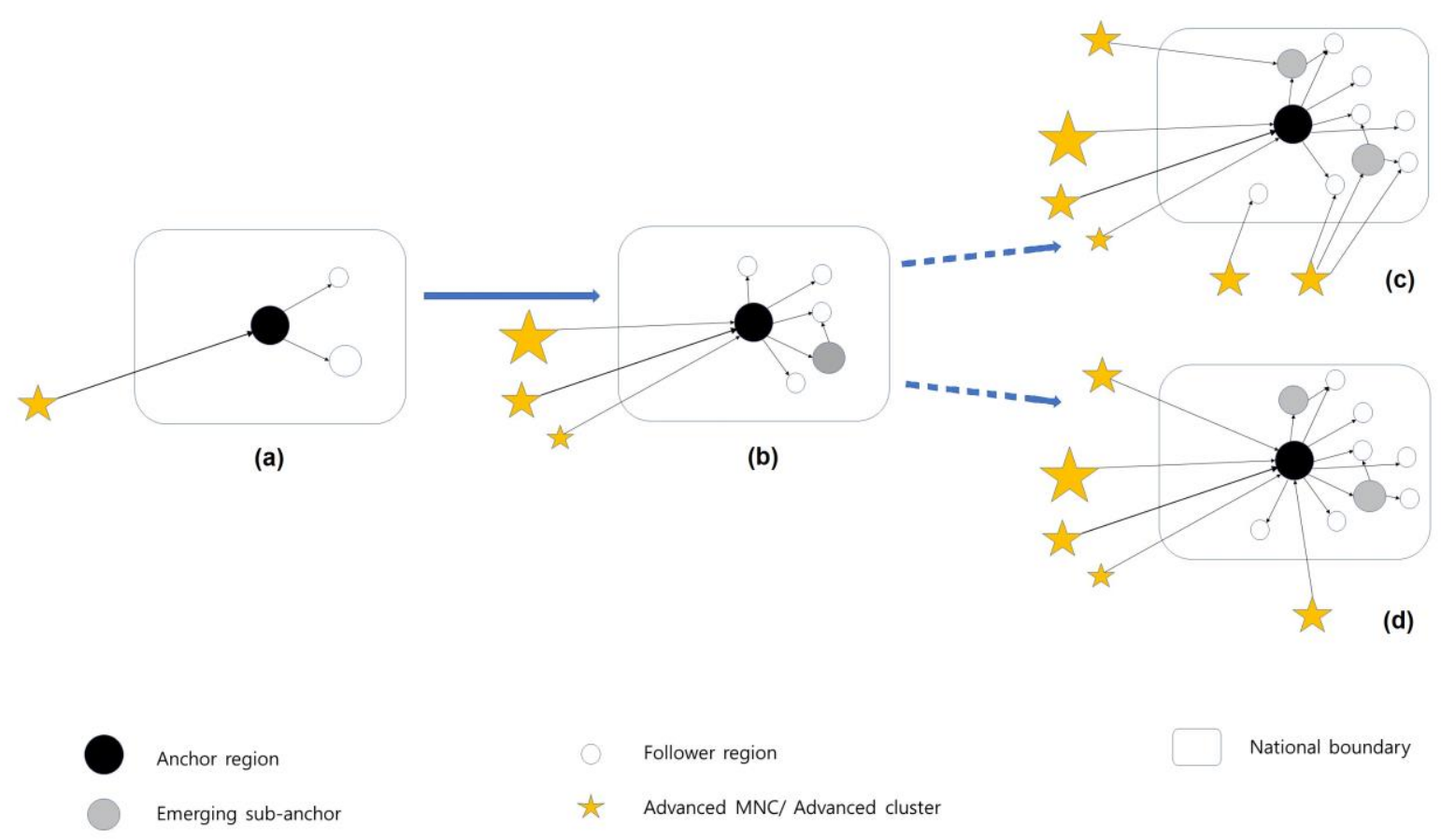

(a) Dependent NSI, (b) Emerging NSI, (c) Globalized RIS (d) Closed Globalization of NSI

Figure 1 Two scenarios for changes in inter-regional networks

Let's consider two scenarios involving changes in interregional networks, within a NSI. Initially, as most regional economic literature predicts, an anchor region would emerge. 
This region would be topologically similar to a transportation network structure in a colonial economy, as described by dependency theorist (Slater, 1975) and can therefore be called “dependent NSI (a)." In this phase, advanced technology comes from outside the NSI, and the anchor region within the NSI can assimilate foreign technology, produce less advanced technology and supply it to the other regions in the country. At this stage, the national economy is highly dependent on foreign technology. Successful industrialization and technological development will transform dependent NSI (a) in Figure 1) to what we call emerging NSI (b) in Figure 1). At this stage, the anchor region has more connections with advanced MNCs, or advanced industrial clusters receiving technology from multiple sources. At the same time, the anchor region's capacity to serve as a regional innovation system increases, and the region can provide a considerable amount of more advanced technology to its follower regions. Thus far, there is little to debate.

Figures 1 (c) and (d) show the different scenarios for the evolution of inter-regional technology transfer networks. Both scenarios show, that, alongside economic growth and industrial upgrading, new regions will need to use more advanced technology, thereby joining networks. The way in which regions join networks is, however, different in each scenario. If the national boundary and NSI is only one of multiple scales on which knowledge is produced, we will see a structure like (c), which we call globalization of RIS. The national boundary is visible, but extremely porous. New entrants to the system form networks with foreign regions and with the original anchor region of the NSI. In the transition from emerging NSI (b) to globalised RIS (c), the capacity of the anchor region as the importer and producer of technology might increase in absolute terms. However, as many other regions form networks with overseas sources of technology, the anchor region's relative importance within NSI will decrease.

This viewpoint is implicit within the major branches of economic geography. Evolutionary economic geographers, for example, do not explicitly deny the importance of NSI, but pay little attention to it. In their theoretical framework, exogenous factors are important, but whether these factors come from within the national economy or outside has attracted little attention (Trippl, Grillitsch, and Isaksen 2017). In relational approaches to economic geography, it is often assumed that a region acquires technology directly from overseas sources. Global production networks, for example, tend to regard the source of the new knowledge as an MNC, when, for example, they discuss strategic coupling between the MNC and the hosting region (Yeung 2009). Similarly, Bathelt, Malmberg, and Maskell 
(2004)'s conceptualization of a global pipeline does not seriously consider national boundaries, either.

The second scenario is the transition from (b) to (d), shown in Figure 1, or from emerging NSI to globalized NSI. In a globalized NSI, the relative importance of an anchor region does not decrease. The anchor region forms networks with more sources of foreign technology, produces more technology itself, and sells more technology to other regions within the NSI. Some of the regions that are at first completely dependent on the anchor region later evolve into sub-anchors, which continue to be dependent on the anchor region but, at the same time, can offer technology to other regions. Since most regional actors rely on the anchor region, the efficiency of information diffusion is, in large part, determined by the anchor region.

\section{Data and methods}

Patent licensing as a measure of technology flow

We use patent licensing as a measure of knowledge flow. We choose patent licensing records rather than often-used measures such as patent citation and co-authorship for various reasons.

Many of the existing studies on technology flows, including learning and diffusion, are based on the analysis of patent citation records (Jaffe, Trajtenberg, and Henderson 1993, Hu and Jaffe 2003, Maruseth and Verspagen 2002). The introduction of patent citation data certainly marked a significant development in the relevant areas of research, as it provides one of the rare paper trails for knowledge flow. The fact that citations show the direction of technology flow (since the cited patent is the origin of the technology and the citing patent its destination) is also important. However, the value of citations is limited by the fact that citing is a low-cost activity. An inventor and her agent might add citations just to make their application look comprehensive, just as an academic might add citations to show his wide reading. In addition, patent examiners from patent granting authorities may add citations if they discover uncited but related patents. Patent citations, then, cannot differentiate important flows of knowledge from related precedent patents that may or may not have affected the invention of the citing patent (Vernon Henderson 2007).

Another widely-used measure of technology flow is the co-authorship of scientific papers and patents (Jaffe, Trajtenberg, and Henderson 1993, Hu and Jaffe 2003, Peri 2005, Park and Lee 2006, Sorenson, Rivkin, and Fleming 2006, Park 2011, Choe et al. 2016, Zhang, 
Guan, and Liu 2014, Kim and Park 2015). Unlike patent citations, co-authorship is highly likely to reflect real interactions among authors and inventors. However, with co-authorship data, it is difficult to see the direction of information flow. In technology transfer research, the direction of the technology flow is of prime importance; thus, co-authorship data is not very useful.

In addition, neither citation nor co-authorship show the economic value of the technology. A patent is granted if the idea is new and its economic impacts are not guaranteed. Many patents never even result in actual production. Citation and co-authorship can therefore show the flow of knowledge, but not that of economically valuable technology. There have been attempts to find a variable within patent records that correlates with the economic value of the patent (Tong and Frame 1994, Reitzig 2003). A diverse set of variables have been tested, including the number of claims, the number of renewals, the sectorial diversity of cited patents, the sectorial diversity of citing patents, and the number of citations. Most of these have some positive correlation with the economic value of patents. However, these are indirect measures at best (Van Zeebroeck 2011, Gambardella, Harhoff, and Verspagen 2008, Hall, Jaffe, and Trajtenberg 2005).

The use of patent licensing data overcomes all of these problems. First, a licensee makes the conscious decision to use a patent because she understands the economic value of that patent: this solves the economic value problem. Second, patent licensing data combines the merits of citation records and those of co-authorship. As in patent citations, patent licenses clearly reference the source and destination of technology flows. At the same time, like co-authorship data, the licensing records show real exchange of information. The licensing contract requires complex decision making by both parties about the availability, quality, usefulness, and price of the patents concerned; each of these requires intensive interactions between the two parties.

Despite these clear advantages, patent licensing has not been much utilized to date, mainly due to its unavailability. A regulatory body cannot require businesses to report their licensing of patents because the use of patents is directly related to a firm's production technology, revelation of which might damage the firm's competitiveness. That is why databases of patent licensing almost never cover a country's full licensing activities. Records collected by management consulting firms are occasionally available but they are rarely comprehensive. For this paper, we acquired the licensing records database of China's State Intellectual Property Office (SIPO). Combined with the address information available in patent records, this database allowed us to track spatial technology flows. 
Data

We estimated the region-to-region technology flow network between the licensor (patent owner) and licensee (purchaser) from the Chinese patent licensing database obtained from SIPO. Under the regulations of the Patent Licensing Contract Recording Procedures (PLCRP), patent contract information - detailing the two parties, their addresses and the patent numbers - is submitted and examined by the authorities. We collected the annually updated data set from 1999 to 2013 that contains 32,551 cases of patent licensing information including patent title, the address of the licensee, application number, the assignee, date of filing, and license type.

Our unit of analysis is a combination of the prefecture-level city and the municipality. In Chinese regional analyses, some researchers use province as the unit of analysis; however, the Chinese provinces are simply too large to contain a regional economy. For example, the biggest one, Xinjiang, is roughly the size of Saudi Arabia and bigger than every Western European country. Further, there is huge variation in the sizes of the provinces. Xinjiang is 262 times as big as Shanghai that is municipality or provincial-level city. As such, for most of provinces, the boundaries do not always correspond with the boundaries of economic activities. The appropriate units for analysis are the metropolitan statistical areas and consolidated metropolitan statistical areas used in the US; however, China does not use these geographical units in its official statistics. The closest Chinese equivalent we could find was the prefecture-level city. There are 177 of them if we include the Inner Mongolian leagues and various ethnic minority groups' autonomous prefectures. To these 177 , we added four municipalities, that is, Beijing, Shanghai, Tianjin, and Chongqing. We did so because the municipalities' areas are comparable to those of prefecture-level cities even if the former's administrative status is the same as that of provinces. Thus, we have a total of 181 regions in our database.

The patents' locations could be identified by the address information, using China's patent search system. Patents with unidentifiable addresses or those licensed by individuals were removed because we wanted to focus on inter-organizational transactions. We therefore selected 25,773 Chinese-owned patents transferred between domestic cities and 6,778 non-Chinese-owned patents. Because we wanted to find a stable pattern of inter-regional knowledge flows, we had to disregard one-time, accidental flows. We chose a cut-off value of five licensing cases. 
Metrics for the analyses of technology transfer networks

Because of the way our database is organized, we could use a small-world network structure to test our hypothesis. The concept of a "small-world network structure" is drawn from Watts and Strogatz (1998) who explains the presence of a small-world structure in various natural and social systems. Small-world networks occur when a randomly selected node is connected to another randomly selected node, without going through too many intermediary nodes. Numerous empirical studies have drawn on this work (Kogut and Walker 2001, Chen and Guan 2010, Balconi, Breschi, and Lissoni 2004, Uzzi and Spiro 2005), and researchers in innovation studies have used this research to explain knowledge exchange among individuals, organizations, and countries (Newman 2001, Watts and Strogatz 1998, Reitzig 2003, Cowan and Jonard 2004, Van Zeebroeck 2011, Kogut and Walker 2001).

Our database includes both networks involving Chinese cities and networks between a Chinese region and an overseas technology sources. If many Chinese cities are connected with overseas sources, this will cause the network structure to appear more fragmented. On the other hand, if only one anchor region is connected to an overseas source of technology, then the networks will appear much less fragmented.

We tested this using the small world quotient (SWQ) (Everton 2012, Gulati, Sytch, and Tatarynowicz 2012). The index is calculated by first estimating both the clustering coefficient (CC) and average path distance (AP). Then, these estimates are normalized by dividing $\mathrm{CC}$ and AP values by the corresponding values of $\mathrm{CC}$ and AP, respectively, obtained from a random network, as follows ${ }^{1}$ :

$$
S W Q=\left[\frac{C C_{\text {actual }}}{C C_{\text {random }}}\right] /\left[\frac{A P_{\text {actual }}}{A P_{\text {random }}}\right]
$$

In section 5, we use role-equivalence analysis, drawn from network structure analysis, to identify the anchors and their roles, in accordance with social network analysis (Borgatti, Everett, and Johnson 2013). Nodes occupying the same roles are defined as "equivalent nodes" in a network, even if they are not directly connected with each other (Hanneman and Riddle 2005). For instance, two highly equivalent nodes can be substituted for each other because they share the same connections. It is highly probable that a node occupying a

${ }^{1}$ In practice, according to Uzzi (2008) and Everton (2012), a network's SWQ can be estimated by simply dividing the original network's CC by its density. 
specific position is embedded in a similar type of relations as others in a similar position and will, thus, exhibit similar behaviors (Everton, 2012). If we rephrase this concept in terms of the regional technology flow network, equivalent cities are expected to play similar functions in creating, transmitting, and consuming technology across the whole country.

To measure the equivalence of two nodes, we apply a "regular equivalence method," to identify similar role-based patterns. This approach to empirical data processing has the advantage of categorizing the characteristics of the individual nodes into several groups without sacrificing their separate features (De Nooy, Mrvar, and Batagelj 2011, White and Reitz 1983, Doreian 1987). According to Faust (1988) and White and Reitz (1983), the equivalence level between two nodes $i$ and $j$ at iteration $t+1$ is given by:

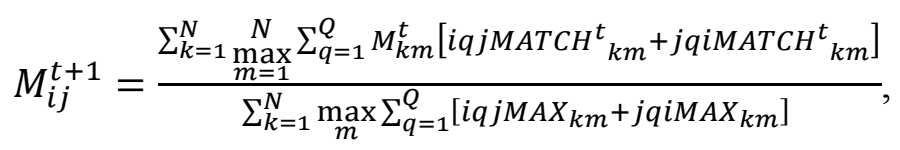

where $N$ is the number of actors, $Q$ is the number of relations, iqjMAX $X_{k m}=$ $\max \left(x_{i k q}, x_{j m q}\right)+\max \left(x_{k i q}, x_{m j q}\right), i q j M A T C H_{k m}=\min \left(x_{i k q}, x_{j m q}\right)+\min \left(x_{k i q}, x_{m j q}\right)$, and $x_{i k q}$ is the value of the tie from $i$ to $j$ on relation $q$. This index measures the weighted match of how well $i$ 's ties are matched by $j$ 's ties, and vice versa. If $i$ and $j$ are perfectly matched (i.e. equivalent), then it equals the maximum value of the sum of the degrees of $i$ and $j$.

We also apply other familiar metrics used in social network analysis, such as inter-node level centralities, degree centrality, betweenness centrality, and O-I index. The former two indices are generally acknowledged to capture the in/out flow degree of nodes, and their "brokering" roles, respectively (Borgatti, Everett, and Johnson 2013). The O-I index shows whether a particular node is a provider or a consumer in the network, by calculating the ratio of the difference and total degree index. When the value of a node is close to 1 , the number of patents exported is greater than that of those imported, implying that the nodes have higher knowledge quality levels (Choe et al. 2016).

In the following section, we presented the structural characteristics of network by employing topography metrics and small world index. Then, Section 5 identifies the anchor cities, by employing the role-equivalence method, followed by a node-level centralities analysis. Lastly, the presence of technology production hierarchies, and the dynamics of anchor firms are demonstrated. In Section 4, we measure the whole network's network-level structural characteristics, using topography metrics: diameter, centralization, density, centrality, and connectedness. 


\section{Testing the glocalized RIS hypothesis}

The structure of the technology transfer network, calculated using multiple metrics, is illustrated in Table 1. The first noteworthy observation is that the centralization value tends to decrease over time, with increasing de-centralization as the network diameter expands. More specifically, the connections became concentrated in a few central cities, until 2006, well before the centralization score plunged to 0.22 in 2012 . There are consistent structural changes: until 2007, the network diameter remains below 3, but its size increases to 7 after 2007. This implies that, while a surge of new cities caused a sharp increase in the network diameter, the accompanying decrease in centralization shows that the entrants were all connected to the anchor cities.

The direction of centrality shows whether the linkages are inward (in-centrality) or outward (out-centrality) to/from the region. The out-centrality value reaches its maximum (1) in 2004, and continuously decreases thereafter. The in-centrality value, on the other hand, shows a rising trend, despite some fluctuations. The intersectional trend between the two indices represents a distinctive change. As more cities are involved in the technology transfer, the prevailing outflows are reduced, along with increases in the in-centrality level. The density and connectedness indices also reflect the changes which happened in 2007: the density continues to decline with a steep increase of connectedness level after 2008.

In sum, a small number of cities dominate the entire system as sources of technology. In the later part of the period under consideration, more cities joined the network, expanding its size, as indicated by the increase in diameter from 2 in 2002 to 7 in 2012 . This was accompanied by decreasing density, while connectedness continued to increase. In other words, while the new linkages from the new cities contributed to the expansion of the network, the influence of central nodes remained as strong as ever or grew even stronger. In order to perform a more robust analysis of these results, we examined the small-world network structure.

Table 1 Network-level topography analysis result in year

\begin{tabular}{ccccccc}
\hline & Diameter & Centralization & Out-Central & In-Central & Density & Connectedness \\
\hline 2001 & 2 & 0.93 & 0.87 & 0.07 & 0.06 & 0.06 \\
2002 & 2 & 0.89 & 0.85 & 0.09 & 0.05 & 0.05 \\
\hline
\end{tabular}




\begin{tabular}{lllllll}
\hline 2003 & 1 & 0.91 & 0.87 & 0.01 & 0.04 & 0.04 \\
2004 & 1 & 1.00 & 1.00 & 0.07 & 0.06 & 0.06 \\
2005 & 1 & 1.00 & 0.95 & 0.05 & 0.04 & 0.04 \\
2006 & 2 & 1.00 & 0.96 & 0.07 & 0.04 & 0.04 \\
2007 & 3 & 0.76 & 0.73 & 0.06 & 0.03 & 0.04 \\
2008 & 6 & 0.46 & 0.45 & 0.19 & 0.02 & 0.21 \\
2009 & 7 & 0.30 & 0.30 & 0.12 & 0.02 & 0.45 \\
2010 & 7 & 0.32 & 0.32 & 0.15 & 0.02 & 0.44 \\
2011 & 7 & 0.28 & 0.28 & 0.15 & 0.02 & 0.49 \\
2012 & 7 & 0.22 & 0.22 & 0.17 & 0.01 & 0.42 \\
\hline
\end{tabular}

Figure 2 shows the SWQ of the technology diffusion network over time. The initial rise in the earlier period supports our argument for the emergence of a small-world network structure. The coefficient reached over 500 in 2008. However, it then dropped below 100, but showed a gradual increase afterwards. Together, these results are likely to confirm the emergence of the small world structure across cities and time periods. Although there are some fluctuations due to the influx of new cities in the technology transfer network around 2008, the structure seems to remain as a small world. The trend is consistent with Zhang, Guan, and Liu (2014), whose SWQ value from co-authorship also shows an upward trend. The presence of a small-world network is highly correlated with a combination of "high connectivity within regions" and "inter-cluster bridging ties." Dense connections within the regions emerge mainly due to risk aversion and information bias, embedded in licensing contracts. Intangible factors such as reliability, reputation, and informal cliques might reduce the risks involved in technology exploration and the trade costs that dictate preferences for neighboring partners (Gulati and Gargiulo 1999, Zaheer, Gözübüyük, and Milanov 2010).

The bridging ties serve as effective conduits through which a region can access new resources that are typically unavailable through ties with neighbors (Burt 2005, Granovetter 1982). The motivation for an institution within the non-principal region to seek new technology from outside provides a further incentive for that institution to connect with a bridging region (McEvily and Zaheer 1999, Zaheer and Bell 2005). Within such settings, the existence of a small-world network structure reinforces the importance of anchor cities, and plays an influential role in diffusion/learning technologies within the innovation system (Watts and Strogatz 1998, Zhang, Guan, and Liu 2014). 


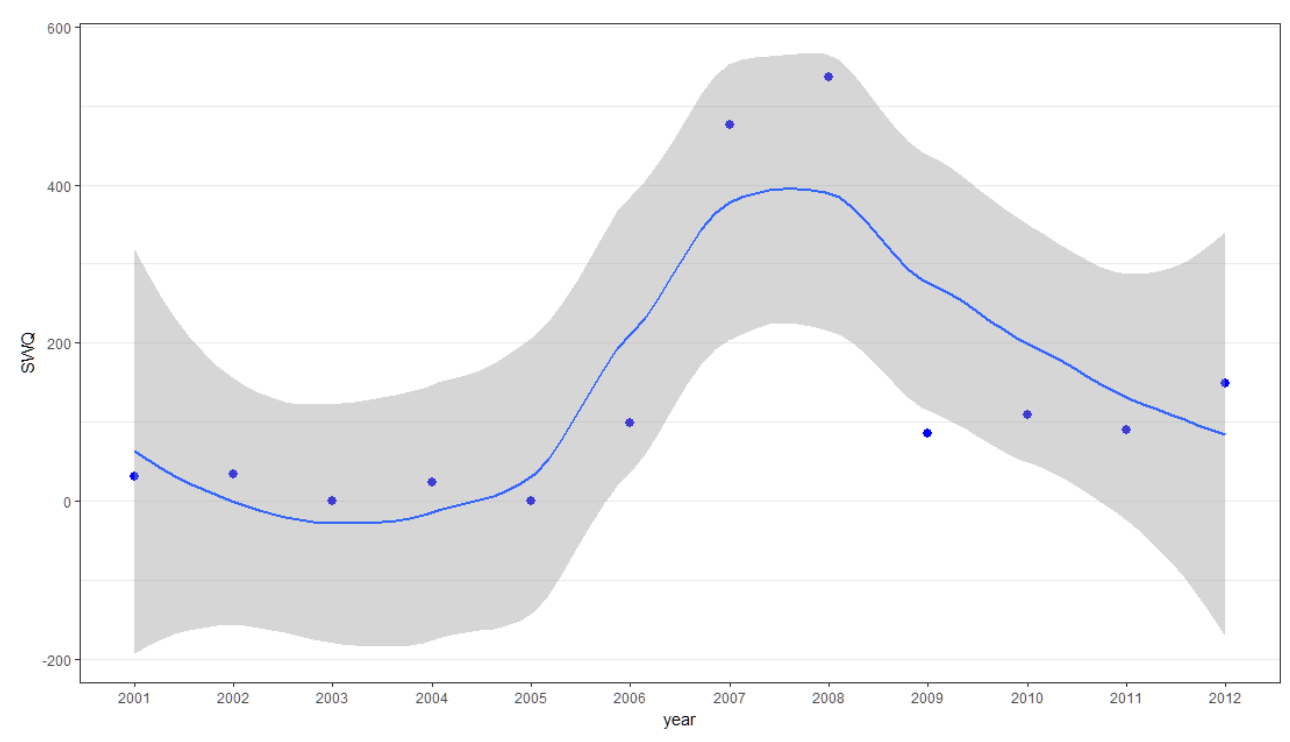

Figure 2 Small world quotient in year

This macro-analysis highlights the structural transformation of the technology transfer network over time. In the earlier stage, that is, until 2006, the technology seems to have a unidirectional flow between a small number of cities, within an overall centralized structure. In the next period, from 2007 to 2008, an increasing number of cities participate in the networks. This sharp expansion may, in part, reflect Chinese government-led policy in the early 2000s to promote the market mechanism for technology transfer; the result is consistent with Zhang, Guan, and Liu's (2014) work. In 1999, China government established the Shanghai Technology Property Rights Exchange to enhance the integration of the financial and property rights markets. Subsequently, in 2005, the Chinese State Council set up the Outline of the Program for the State Long-term Science and Technology Development (2006-2020) that had over 60 supporting policy measures related to the fiscal system, taxation, banking, industries, government purchases, and protection of intellectual property rights, to encourage technology transfer (Yülek and Taylor 2011). These policy changes might have led more firms and public sector institutions to enter the technology transfer market, expanding the network size. This transition process follows a small-world model, with power and influence concentrated in a small number of cities. The balanced in/out centralities hint at interactive transactions, rather than unilateral ones. After 2009, the network appears to be saturated in size, highly connected, and more "small world." 


\section{Exploring the qualities of anchor regions}

The analyses of technology transfer networks in the previous section shows 1) expansion of networks and 2) the persistence of inter-regional hierarchy. Building upon these structural-level findings, this section looks into the micro details. More specifically, we ask the following two questions: 1) which cities are the anchor cities at the top of the hierarchy? and 2) what are the characteristics of the other cities like?

\section{The identification of anchor regions}

Table 2 summarizes the results of our equivalence analysis, divides all 181 cities into eight groups, and displays the averaged values of innovative activities. For clarity, Figure 3 presents four quadrants, plotting the patent growth rate (CAGR) on the y-axis against the in-flow/out-flow (O-I index) levels, and displaying them against a territorial map.

Table 2 Network centralities and (avg.) knowledge activities indices by patterns

\begin{tabular}{|c|c|c|c|c|c|c|c|c|c|c|c|c|c|}
\hline \multirow[t]{3}{*}{ Group } & \multirow{3}{*}{$\begin{array}{c}\text { Sub-Gro } \\
\text { up }\end{array}$} & \multirow{3}{*}{$\begin{array}{l}\text { No. of } \\
\text { Cities }\end{array}$} & \multirow{2}{*}{\multicolumn{3}{|c|}{ Centralities }} & \multirow{3}{*}{$\begin{array}{c}\text { O-I } \\
\text { Index }\end{array}$} & \multirow{2}{*}{\multicolumn{2}{|c|}{$\begin{array}{c}\text { Local patents } \\
\text { purchase }\end{array}$}} & \multirow{3}{*}{$\begin{array}{c}\text { Patents } \\
\text { Applications } \\
\text { Growth } \\
\text { Ratio }\end{array}$} & \multirow{2}{*}{\multicolumn{2}{|c|}{ License Contracts }} & \multirow{3}{*}{$\begin{array}{c}\text { Total } \\
\text { Patents } \\
\text { (per 10000) }\end{array}$} & \multirow{3}{*}{$\begin{array}{l}\text { Overseas } \\
\text { Patents } \\
\text { Adopted }\end{array}$} \\
\hline & & & & & & & & & & & & & \\
\hline & & & $\begin{array}{c}\text { Out-Degr } \\
\text { ee }\end{array}$ & $\begin{array}{c}\text { In-Degre } \\
\mathrm{e}\end{array}$ & $\begin{array}{c}\text { Between- } \\
\text { ness }\end{array}$ & & Total & Ratio & & Licensor & Licensee & & \\
\hline Anchor & 1 & 5 & 38 & 27 & 2503 & 0.1 & 720 & 0.44 & 0.42 & 1502 & 1305 & 39.1 & 782 \\
\hline Fast & 4 & 42 & 10 & 11 & 347 & -0.1 & 168 & 0.37 & 0.36 & 338 & 339 & 10.9 & 62 \\
\hline -Follower & 6 & 24 & 4 & 4 & 118 & 0.02 & 45 & 0.24 & 0.29 & 92 & 82 & 5.90 & 1 \\
\hline \multirow{2}{*}{$\begin{array}{l}\text { Self-sustain } \\
\text { starter }\end{array}$} & 2 & 10 & 2 & 0.9 & 6 & 0.5 & 19 & 0.41 & 0.24 & 38 & 27 & 2.30 & 0.1 \\
\hline & 8 & 11 & 2 & 0.5 & 0 & 0.6 & 15 & 0.00 & 0.28 & 28 & 20 & 2.25 & 0 \\
\hline \multirow{3}{*}{ Depender } & 3 & 11 & 1 & 3 & 6 & -0.7 & 10 & 0.36 & 0.28 & 19 & 41 & 1.84 & 20 \\
\hline & 5 & 73 & 0.6 & 2 & 9 & -0.7 & 8 & 0.34 & 0.27 & 13 & 26 & 1.64 & 0.2 \\
\hline & 7 & 5 & 0.5 & 2 & 0 & -0.7 & 7 & 0.14 & 0.28 & 8 & 22 & 0.68 & 0 \\
\hline
\end{tabular}

The region's patent applications growth rate was plotted on the y-axis to capture that region's basic innovative capacity. The x-axis charts the tendency of the technology activities (i.e. whether the region is importing or exporting patents). The direction of a region's technology flow signifies its receptivity to explore external technology and authority power for its internal knowledge stocks (Capello and Lenzi 2013). The top right quadrant consists of fast-growing cities, which are actively exporting knowledge, while the bottom left quadrant consists of cities lagging in knowledge growth and technologically reliant on others. 


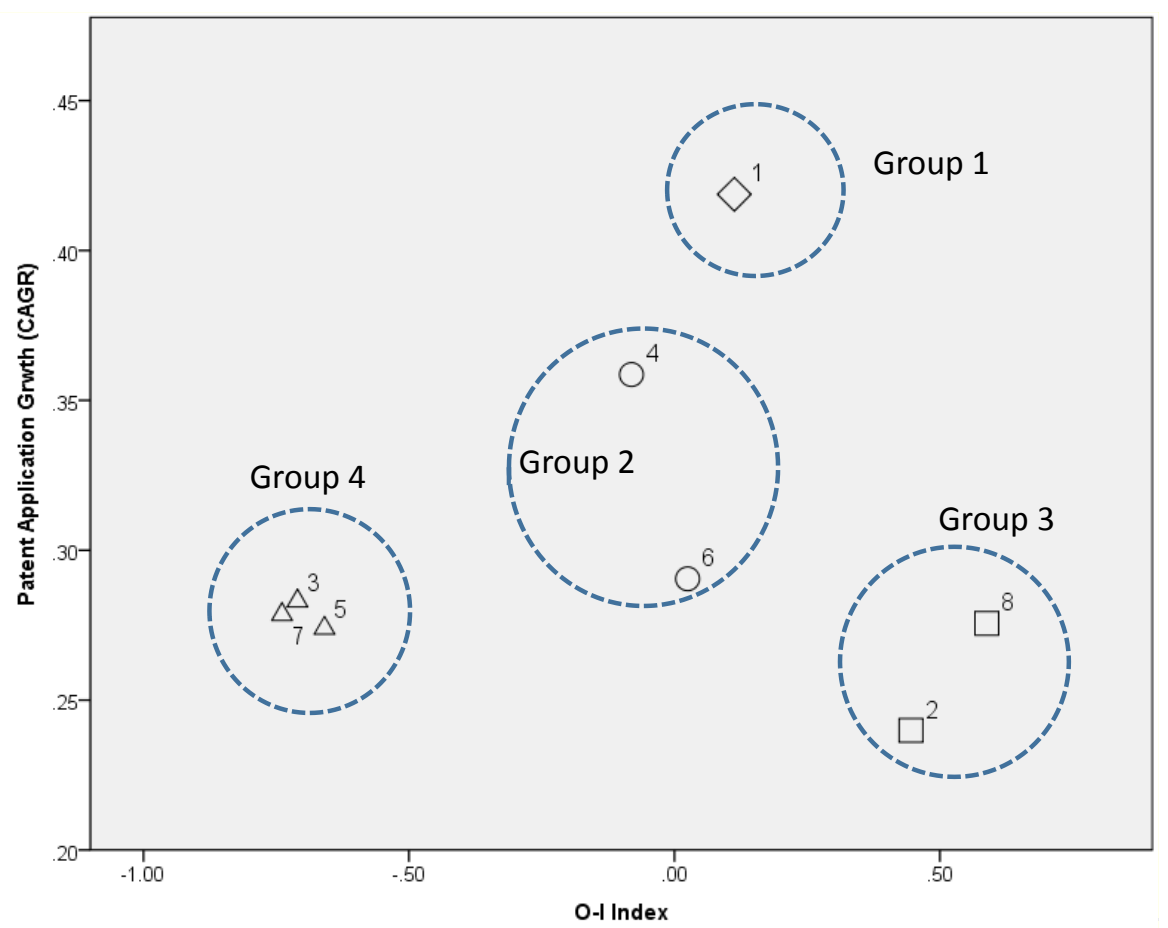

Figure 3 Patterns by equivalent groups

Group 1, the anchor group, consists of five cities: Beijing, Shenzhen, Dongguan, Suzhou, and Shanghai. Beijing centers on the Bohai Gulf Region (BGR), the capital of China. Shenzhen and Dongguan are both located in the Pearl River Delta (PRD) and Suzhou and Shanghai in the Yangtze River Delta (YRD). These three metropolitan areas, the super regions, are the three main drivers of the Chinese economy. Our analysis corroborated the primary role of the three traditional core regions, Beijing, Shenzhen, and Shanghai, but also found that Dongguan and Suzhou are the anchor regions. Both regions display similar patterns in their interactions with neighbor regions. For instance, Dongguan shares a border with Shenzhen and Suzhou with Shanghai. Both import a lot of overseas patents and reproduce local patents.

Table 2 demonstrates that the anchor group's innovative capacities are well above those of other regions across almost all dimensions (i.e. betweenness centrality, patent growth rate, patent production and consumption, total patents, and overseas patents). These regions import a large number of foreign technologies (782), are nodes that connect other regions (with a high betweenness centrality of 2503), and display a high rate of intra-regional technology licensing (720). They also have fast-growing patent applications (0.42) and the highest ratio of local patent consumption (0.44). 
Group 2 includes two subgroups of 66 regions, with similar but lagging patterns, compared with those of the anchor group. Subgroup 4, however, is more similar to the anchor group than the others: with higher centralities (347), overseas technology imports (62), and active technology exchange transactions. Group 4 appears to be at an early stage of development, with higher values of patent production (338) and consumption (339). It seems to be a "fast follower," while Subgroup 6 is a "follower."

Pattern 3, at the bottom right, consists of 21 regions in two groups $(2,8)$. Their pattern is quite distinctive: with a higher O-I index $(0.5,0.6)$, and lower betweenness centrality $(6,0)$, and overseas patent adoption $(0.1,0)$. These two subgroups also have the lowest patent growth rate $(0.24,0.28)$ and more licensor than licensee contracts. This indicates that these regions are specialized in technology creation, without the influx of exogenous technologies. They do not appear to be associated with strong technology importers, but show higher values in out-degree centrality. Given that out-degree centrality is an alternative index for the level of innovative technology capacity, these regions are clearly outperforming the others in their authority power to produce knowledge for other regions.

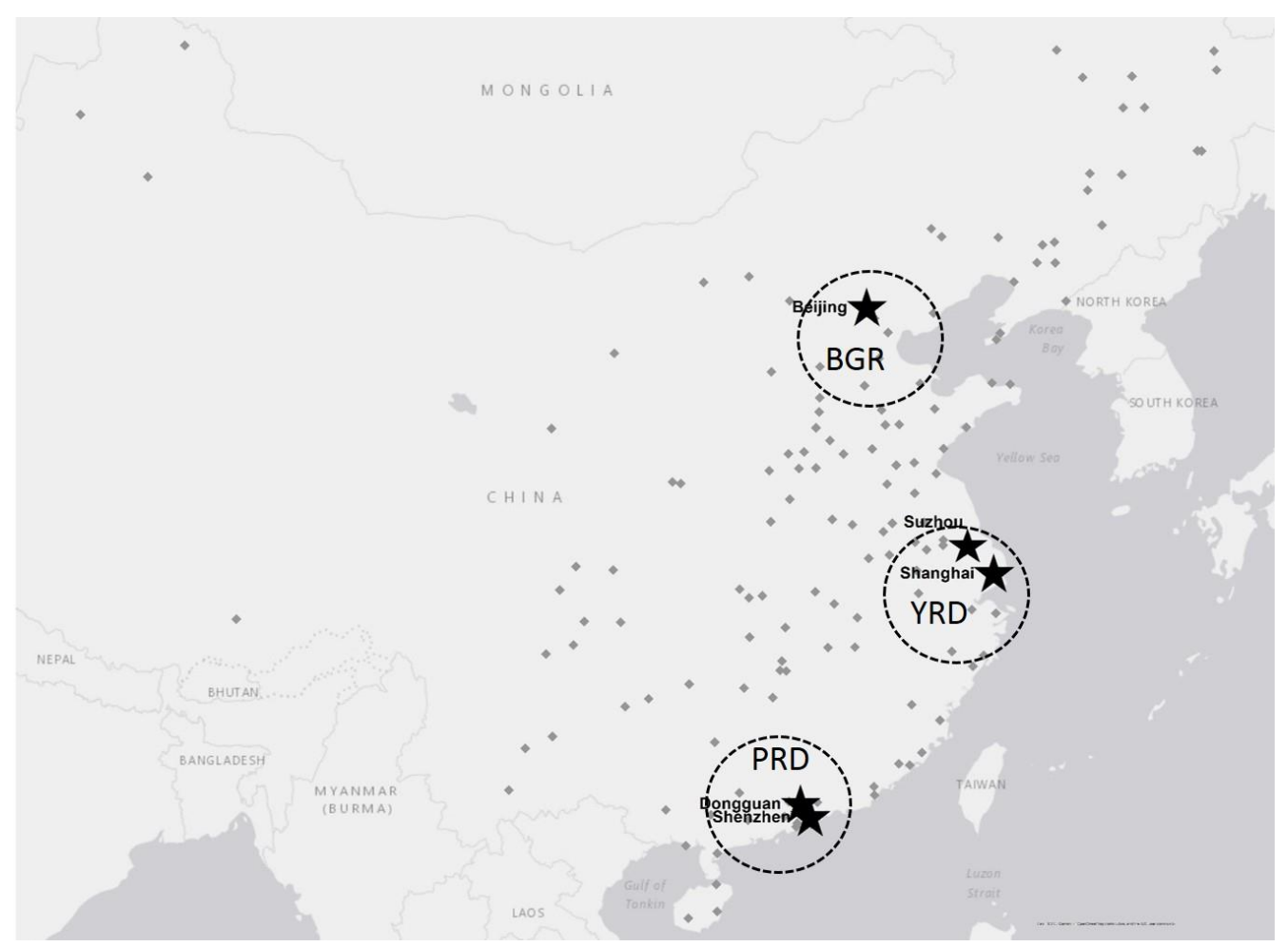

Figure 4 Anchor regions 
Most of the regions fall into Group 4, in the bottom left quadrant. Overall, these regions display lower levels across almost every dimension. This suggests that these regions are at the earliest stage of knowledge exchange and therefore tend to rely on external sources. Strong evidence for this exogenous pattern is shown in the highest negative O-I index and the lowest betweenness centrality value.

The hierarchies of technology flow and the dynamics of anchor regions

In this section, we discuss whether the presence of anchor regions influences the hierarchies of technology production structures and how anchor regions facilitate these dynamics. Figure 5 displays the changes in the regression slope of rank-size distribution over a time series. The rank-size distribution provides information on the extent of the hierarchy between the actors (Meijers and Burger 2010, Parr 2004). We calculated the slope of the rank's regression line according to the region's patent size. The steeply decreasing slope implies that the distribution of the patent size of regions has become more hierarchical in structure. The gap between anchor and other regions continues to gradually increase.

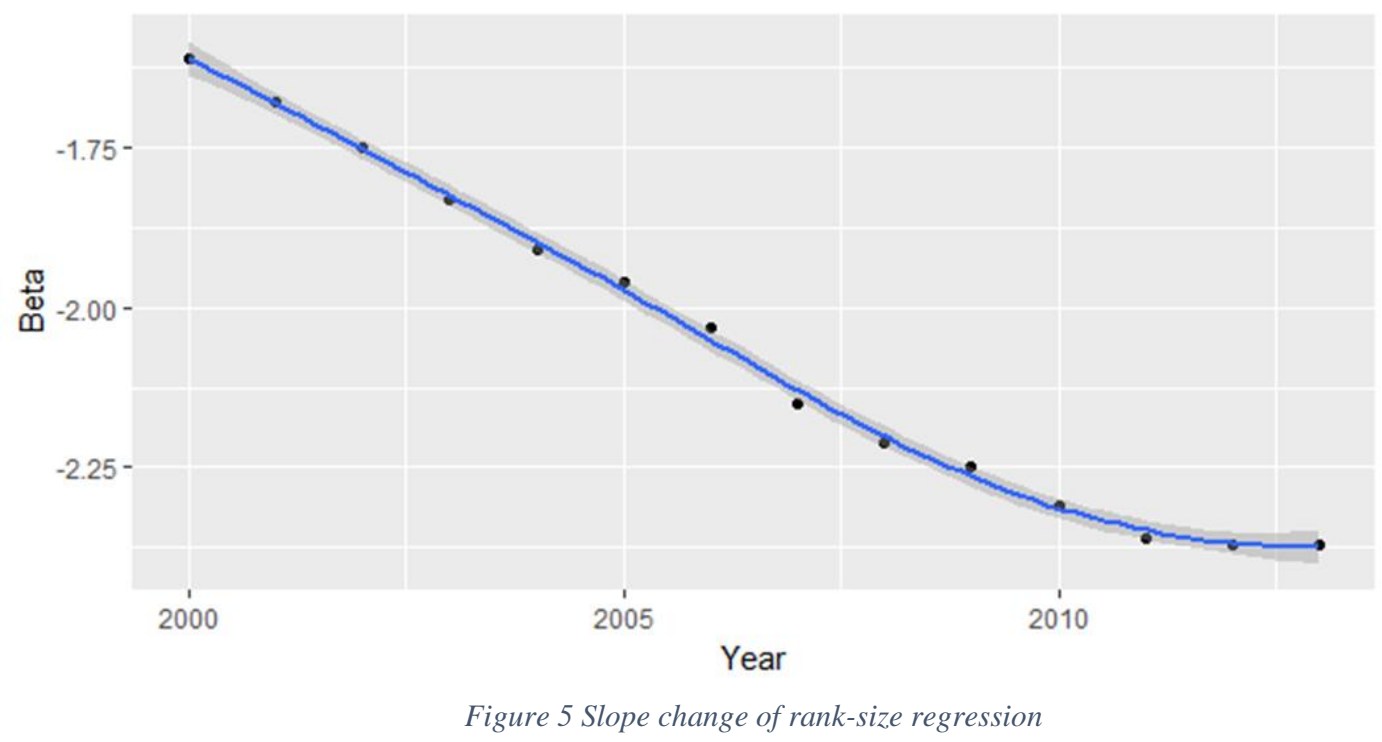

Table 3 presents the transition intervals at which licensees turn into licensors, according to our patent data sources. The interval between a technology consumer importing patents from overseas countries and transforming into a provider might be interpreted as evidence of innovative capacity elevation (Chung and Lee 2015). It also shows how a region that serves a leading role, initiated by exogenous technology, can support other domestic 
regions (Trippl, Grillitsch, and Isaksen 2017). As Kim (1997) suggested, a shorter interval provides one of the mechanisms by which catching-up countries can accelerate their developmental processes, by absorbing high-level technologies from other countries.

The total overseas patent/technology inflows are 6,778. As expected, the majority (51\%) were imported by the anchor regions. Group 2 has the second largest inflows, at $44 \%$. The initial year of foreign technology adoption took place in 2008, but the average interval period year for role transitions from buyer to provider differs across groups. The anchor group took one year for the transition, with a small standard deviation (1). Meanwhile, Group 2 took two years, with higher variances, and Group 4 exhibits a four-year transition period. Group 3 has few cases of total overseas technology adoption and no record of transition experiences. This suggests that the Group 4 regions have little to do with exogenous development.

Table 3 Overseas patents: adoption and transition

\begin{tabular}{|c|c|c|c|c|c|c|}
\hline \multirow{2}{*}{ Patterns } & \multicolumn{2}{|c|}{$\begin{array}{l}\text { Overseas patents } \\
\text { adoption }\end{array}$} & \multirow{2}{*}{$\begin{array}{c}\text { Year of } \\
\text { initial } \\
\text { adoption }\end{array}$} & \multicolumn{3}{|c|}{ Transition interval to patents provide } \\
\hline & $\begin{array}{l}\text { Total } \\
\text { Cases }\end{array}$ & Average & & Cases & Year & St.Dev. \\
\hline Anchor & 3480 & 44.4 & 2008 & 25.6 & 2009 & 1.0 \\
\hline Fast-follower & 2950 & 20.2 & 2008 & 11.8 & 2010 & 1.7 \\
\hline Self-sustain starter & 8 & 8.5 & 2007 & - & - & - \\
\hline Depender & 340 & 12.5 & 2008 & 10.7 & 2012 & 1.5 \\
\hline
\end{tabular}

\section{Theoretical implications and conclusion}

In this paper, we explored the structure of technology flow and found that the year 2007 marked a clear reversal point, after the high concentrations of earlier periods. After 2007, the network expanded quickly, and the influence of anchor regions became stronger, thereby maintaining the spatial hierarchy of regions with regard to innovation activities. Based on the results of the REGE analysis, we classified the anchor regions using the "role-equivalence" measure. These anchor regions provide knowledge after assimilating external technology. We discussed the dynamics of anchor regions, which generate externalities similar to those of a cluster's "anchor firm," to shape capabilities. We then analyzed the dynamics of the anchor regions, which assimilate external knowledge and 
transform it into localized knowledge. Our analysis measured the transition time period from licensor to licensee and expanded the scope of previous studies by exploring the path-dependence phenomenon. Sun and Liu (2016) suggest that the role of anchor regions is to transform technology from external regions and countries into localized knowledge, thus potentially serving as a conduit for new ideas, technologies, and knowledge for other neighboring regions.

Despite the literature emphasizing the role of "weightless technology" in the development of a region, which might result in the disappearance of the regional hierarchy, our analysis suggests that anchor regions have maintained their positions by reproducing new technology from exogenous technology sources. The small-world network structure provides an effective way for one node to reach any other node in the entire system at the highest possible speed of knowledge transmission, as suggested by Gulati, Sytch, and Tatarynowicz (2012) and Cowan and Jonard (2004). From the perspective of a catching-up country, this might result in a "selective choice" policy, for maximum efficiency in fast-growing economies (Branstetter 2001, Camagni and Capello 2013). The efficiency and externality caused by the small-world structure, however, carries the potential risk of excessive homogenization. This potentiality makes the regional innovation system less attractive, which limits the development of new bridging ties to overseas regions (Gulati, Sytch, and Tatarynowicz 2012).

\section{References}

Asheim, Bjørn, and Meric S Gertler. 2005. "The geography of innovation: regional innovation systems." The Oxford handbook of innovation:291-317.

Audretsch, David B, and Max Keilbach. 2008. "Resolving the knowledge paradox: Knowledge-spillover entrepreneurship and economic growth." Research Policy no. 37 (10):1697-1705.

Balconi, Margherita, Stefano Breschi, and Francesco Lissoni. 2004. "Networks of inventors and the role of academia: an exploration of Italian patent data." Research Policy no. 33 (1):127-145.

Bathelt, Harald, and Sebastian Henn. 2014. "The geographies of knowledge transfers over distance: toward a typology." Environment and Planning A no. 46 (6):1403-1424.

Bathelt, Harald, Anders Malmberg, and Peter Maskell. 2004. "Clusters and knowledge: local buzz, global pipelines and the process of knowledge creation." Progress in human geography no. 28 (1):31-56.

Borgatti, Stephen P., Martin G. Everett, and Jeffrey C. Johnson. 2013. Analyzing Social Networks: SAGE.

Boschma, Ron A, Pierre-Alexandre Balland, and Dieter Franz Kogler. 2014. "Relatedness and technological change in cities: the rise and fall of technological knowledge in US metropolitan areas from 1981 to 2010." Industrial and Corporate Change no. 24 (1):223-250. 
Boschma, Ron A, and Anne LJ Ter Wal. 2007. "Knowledge networks and innovative performance in an industrial district: the case of a footwear district in the South of Italy." Industry and Innovation no. 14 (2):177-199.

Branstetter, Lee G. 2001. "Are knowledge spillovers international or intranational in scope?: Microeconometric evidence from the US and Japan." Journal of International Economics no. 53 (1):53-79.

Burt, Ronald S. 2005. Brokerage and closure: An introduction to social capital: Oxford university press.

Camagni, Roberto, and Roberta Capello. 2013. "Regional Innovation Patterns and the EU Regional Policy Reform: Toward Smart Innovation Policies." Growth and Change no. 44 (2):355-389.

Caniëls, Marjolein CJ, and Bart Verspagen. 2001. "Barriers to knowledge spillovers and regional convergence in an evolutionary model." Journal of evolutionary economics no. 11 (3):307-329.

Cantner, Uwe, and Holger Graf. 2006. "The network of innovators in Jena: An application of social network analysis." Research Policy no. 35 (4):463-480.

Capello, Roberta, Andrea Caragliu, and Peter Nijkamp. 2010. "TERRITORIAL CAPITAL AND REGIONAL GROWTH: INCREASING RETURNS IN KNOWLEDGE USE." Tijdschrift voor economische en sociale geografie no. 102 (4):385-405.

Capello, Roberta, and Camilla Lenzi. 2013. "Territorial patterns of innovation: a taxonomy of innovative regions in Europe." The Annals of Regional Science no. 51 (1):119-154.

Capello, Roberta, and Attila Varga. 2013. "Knowledge creation and knowledge diffusion in space and regional innovation performance: introductory remarks." The Annals of Regional Science no. 51 (1):113-118. doi: papers3://publication/doi/10.1007/s00168-013-0569-x.

Capon, Noel, and Rashi Glazer. 1987. "Marketing and technology: a strategic coalignment." The Journal of Marketing:1-14.

Chatterji, Deb. 1996. "Accessing external sources of technology." Research-Technology Management no. 39 (2):48-56.

Chatterji, Deb, and Thomas A Manuel. 1993. "Benefiting from external sources of technology." Research-Technology Management no. 36 (6):21-26.

Chen, Zifeng, and Jiancheng Guan. 2010. "The impact of small world on innovation: An empirical study of 16 countries." Journal of Informetrics no. 4 (1):97-106.

Choe, Hochull, Duk Hee Lee, Hee Dae Kim, and Il Won Seo. 2016. "Structural properties and inter-organizational knowledge flows of patent citation network: The case of organic solar cells." Renewable and Sustainable Energy Reviews no. 55 (C):361-370.

Choi, Kyunghee, and Deokho Cho. 2015. "An effect analysis of regional research and development support policies: focused on Gyeongbuk province in Korea." International Journal of Urban Sciences no. 19 (3):320-342.

Choi, Myoungsub, and Taelim Choi. 2017. "Agglomeration, productivity, and high-growth firms in the manufacturing sector of South Korea." International Journal of Urban Sciences no. 21 (1):58-71.

Chung, Moon Young, and Keun Lee. 2015. "How Absorptive Capacity is Formed in a Latecomer Economy: Different Roles of Foreign Patent and Know-how Licensing in Korea." WORLD DEVELOPMENT no. 66 (C):678-694. doi: papers3://publication/doi/10.1016/j.worlddev.2014.09.010.

Coe, David T, and Elhanan Helpman. 1995. "International r\&d spillovers." European economic review no. 39 (5):859-887.

Cohen, Wesley M, and Daniel A Levinthal. 1989. "Innovation and learning: the two faces of R \& D." The economic journal no. 99 (397):569-596. 
Cooke, P. 2004. "The role of research in regional innovation systems: new models meeting knowledge economy demands." International Journal of Technology Management no. 28 (3/4/5/6):507.

Cowan, Robin, and Nicolas Jonard. 2004. "Network structure and the diffusion of knowledge." Journal of economic Dynamics and Control no. 28 (8):1557-1575.

Dalby, Simon, and Gearóid Ó Tuathail. 1998. Rethinking geopolitics: Psychology Press.

De Nooy, Wouter, Andrej Mrvar, and Vladimir Batagelj. 2011. Exploratory social network analysis with Pajek. Vol. 27: Cambridge University Press.

Doreian, Patrick. 1987. "Measuring regular equivalence in symmetric structures." Social Networks no. 9 (2):89-107. doi: papers3://publication/doi/10.1016/0378-8733(87)90008-6.

Ernst, Dieter, and Linsu Kim. 2002. "Global production networks, knowledge diffusion, and local capability formation." Research Policy no. 31 (8-9):1417-1429. doi: papers3://publication/doi/10.1016/S0048-7333(02)00072-0.

Everton, Sean F. 2012. Disrupting Dark Networks, REGE Model: Cambridge University Press.

Faust, Katherine. 1988. "Comparison of methods for positional analysis: Structural and general equivalences." Social networks no. 10 (4):313-341.

Feldman, Maryann. 2003. "The locational dynamics of the US biotech industry: knowledge externalities and the anchor hypothesis." Industry and Innovation no. 10 (3):311-329.

Gambardella, Alfonso, Dietmar Harhoff, and Bart Verspagen. 2008. "The value of European patents." European Management Review no. 5 (2):69-84.

Granovetter, Mark. 1982. "Alienation reconsidered: The strength of weak ties."

Granstrand, Ove, Erik Bohlin, Christer Oskarsson, and Niklas Sjöberg. 1992. "External technology acquisition in large multi-technology corporations." $R \& D$ Management no. 22 (2):111-134.

Gulati, Ranjay, and Martin Gargiulo. 1999. "Where do interorganizational networks come from?" American journal of sociology no. 104 (5):1439-1493.

Gulati, Ranjay, Maxim Sytch, and Adam Tatarynowicz. 2012. "The rise and fall of small worlds: Exploring the dynamics of social structure." Organization Science no. 23 (2):449-471.

Hall, Bronwyn H, Adam Jaffe, and Manuel Trajtenberg. 2005. "Market value and patent citations." RAND Journal of economics:16-38.

Hanneman, Robert A, and Mark Riddle. 2005. Introduction to social network methods. University of California Riverside.

Hong, Wei. 2008. "Decline of the center: The decentralizing process of knowledge transfer of Chinese universities from 1985 to 2004." Research Policy no. 37 (4):580-595.

Hu, Albert G. Z., and Adam B. Jaffe. 2003. "Patent citations and international knowledge flow: the cases of Korea and Taiwan." International Journal of Industrial Organization no. 21 (6):849-880.

Huber, George P. 1991. "Organizational learning: The contributing processes and the literatures." Organization science no. 2 (1):88-115.

Jaffe, Adam B, Manuel Trajtenberg, and Rebecca Henderson. 1993. "Geographic localization of knowledge spillovers as evidenced by patent citations." the Quarterly journal of Economics:577-598.

Jiang, Min, and Euijune Kim. 2016. "Impact of high-speed railroad on regional income inequalities in China and Korea." International Journal of Urban Sciences no. 20 (3):393-406.

Jonash, Ronald S. 1996. "Strategic technology leveraging: making outsourcing work for you." Research-Technology Management no. 39 (2):19-25. 
Kim, Gyu Hwan, and In Kwon Park. 2015. "Agglomeration economies in knowledge production over the industry life cycle: evidence from the ICT industry in the Seoul Capital Area, South Korea." International Journal of Urban Sciences no. 19 (3):400-417. doi: 10.1080/12265934.2015.1083461.

Kim, Linsu. 1997. Imitation to innovation: The dynamics of Korea's technological learning: Harvard Business Press.

Kim, Linsu. 1998. "Technology policies and strategies for developing countries: lessons from the Korean experience." Technology Analysis \& Strategic Management no. 10 (3):311-324.

Kogut, Bruce, and Gordon Walker. 2001. "The small world of Germany and the durability of national networks." American sociological review:317-335.

Liu, Weidong, and Henry Wai-chung Yeung. 2008. "China's dynamic industrial sector: the automobile industry." Eurasian Geography and Economics no. 49 (5):523-548.

Liu, Xielin, and Steven White. 2001. "Comparing innovation systems: a framework and application to China's transitional context." Research policy no. 30 (7):1091-1114.

Maruseth, PB, and B Verspagen. 2002. "Knowledge-spillovers in Europe: a patent citation analysis." Scandinavian Journal of Economics no. 104 (4):531-545.

McEvily, Bill, and Akbar Zaheer. 1999. "Bridging ties: A source of firm heterogeneity in competitive capabilities." Strategic management journal:1133-1156.

Meijers, Evert J, and Martijn J Burger. 2010. "Spatial structure and productivity in US metropolitan areas." Environment and Planning A no. 42 (6):1383-1402.

Newman, Mark EJ. 2001. "Clustering and preferential attachment in growing networks." Physical review E no. 64 (2):025102.

Park, Jong Hwa. 2016. "Brokerage activities in regional innovation networks: the case of Daegu Technopark in Korea." International Journal of Urban Sciences no. 20 (2):260-284.

Park, Kyoo-Ho. 2011. "Catch-up process and underlying knowledge flows: focusing on geographic localisation at a national dimension." Asian Journal of Technology Innovation no. 19 (1):85-100. doi: papers3://publication/doi/10.1080/19761597.2011.578425.

Park, Kyoo-Ho, and Keun Lee. 2006. "Linking the technological regime to the technological catch-up: analyzing Korea and Taiwan using the US patent data." Industrial and Corporate Change no. 15 (4):715-753.

Parr, John. 2004. "The polycentric urban region: a closer inspection." Regional studies no. 38 (3):231-240.

Peri, Giovanni. 2005. "Determinants of knowledge flows and their effect on innovation." Review of Economics and Statistics no. 87 (2):308-322.

Powell, Walter. 2003. "Neither market nor hierarchy." The sociology of organizations: classic, contemporary, and critical readings no. 315:104-117.

Pyke, Frank, and Werner Sengenberger. 1992. Industrial districts and local economic regeneration: International Labour Organisation.

Reitzig, Markus. 2003. "What determines patent value?: Insights from the semiconductor industry." Research Policy no. 32 (1):13-26.

Russo, Margherita. 1985. "Technical change and the industrial district: the role of interfirm relations in the growth and transformation of ceramic tile production in Italy." Research Policy no. 14 (6):329-343.

Sonn, Jung Won, and In Kwon Park. 2011. "The increasing importance of agglomeration economies hidden behind convergence: Geography of knowledge production." Urban Studies no. 48 (10):2180-2194. 
Sorenson, Olav, Jan W. Rivkin, and Lee Fleming. 2006. "Complexity, networks and knowledge flow." Research Policy no. 35 (7):994-1017. doi: papers3://publication/doi/10.1016/j.respol.2006.05.002.

Storper, Michael, and Richard Walker. 1989. The capitalist imperative. Oxford: Blackwell.

Sun, Yutao, and Kai Liu. 2016. "Proximity effect, preferential attachment and path dependence in inter-regional network: a case of China's technology transaction." Scientometrics no. 108 (1):201-220.

Ter Wal, Anne LJ, and Ron A Boschma. 2009. "Applying social network analysis in economic geography: framing some key analytic issues." The Annals of Regional Science no. 43 (3):739-756.

Tong, Xuesong, and J Davidson Frame. 1994. "Measuring national technological performance with patent claims data." Research Policy no. 23 (2):133-141.

Trippl, Michaela, Markus Grillitsch, and Arne Isaksen. 2017. "Exogenous sources of regional industrial change." Progress in Human Geography. doi: https://doi.org/10.1177/0309132517700982.

Uzzi, Brian. 2008. "A social network's changing statistical properties and the quality of human innovation." Journal of Physics A: Mathematical and Theoretical no. 41 (22):224023.

Uzzi, Brian, and Jarrett Spiro. 2005. "Collaboration and creativity: The small world problem." American journal of sociology no. 111 (2):447-504.

Van Zeebroeck, Nicolas. 2011. "The puzzle of patent value indicators." Economics of innovation and new technology no. 20 (1):33-62.

Vernon Henderson, J. 2007. "Understanding knowledge spillovers." Regional Science and Urban Economics no. 37 (4):497-508. doi: https://doi.org/10.1016/j.regsciurbeco.2006.11.010.

Verspagen, Bart. 2010. "The spatial hierarchy of technological change and economic development in Europe." The Annals of Regional Science no. 45 (1):109-132.

Von Hippel, Eric. 1994. "“Sticky information" and the locus of problem solving: implications for innovation." Management science no. 40 (4):429-439.

Wang, Yuandi, Xin Pan, Lutao Ning, Jian Li, and Jin Chen. 2015. "Technology exchange patterns in China: an analysis of regional data." The Journal of Technology Transfer no. 40 (2):252-272.

Watts, Duncan J, and Steven H Strogatz. 1998. "Collective dynamics of'small-world'networks." nature no. 393 (6684):440.

White, Douglas R, and Karl P Reitz. 1983. "Graph and semigroup homomorphisms on networks of relations." Social Networks no. 5 (2):193-234.

Yülek, Murat A, and Travis K Taylor. 2011. Designing public procurement policy in developing countries: how to foster technology transfer and industrialization in the global economy: Springer Science \& Business Media.

Yeung, Henry Wai-chung. 2009. "Regional development and the competitive dynamics of global production networks: an East Asian perspective." Regional Studies no. 43 (3):325-351.

Yeung, Henry Wai-chung. 2016. Strategic coupling: East Asian industrial transformation in the new global economy: Cornell University Press.

Zaheer, Akbar, and Geoffrey G Bell. 2005. "Benefiting from network position: firm capabilities, structural holes, and performance." Strategic management journal no. 26 (9):809-825.

Zaheer, Akbar, Remzi Gözübüyük, and Hana Milanov. 2010. "It's the connections: The network perspective in interorganizational research." The Academy of Management Perspectives no. 24 (1):62-77. 
Zhang, Gupeng, Jiancheng Guan, and Xielin Liu. 2014. "The impact of small world on patent productivity in China." Scientometrics no. 98 (2):945-960. 